\title{
REVERSES AND VARIATIONS OF YOUNG'S INEQUALITIES WITH KANTOROVICH CONSTANT
}

\author{
HAISONG CAO AND JUNLIANG WU
}

Abstract. In this paper, we obtain some improved Young and Heinz inequalities and the reverse versions for scalars and matrices with Kantorovich constant, equipped with the Hilbert-Schmidt norm, and then we present the corresponding interpolations of recent refinements in the literature.

Mathematics subject classification (2010): 15A48, 15A60, 47A63.

Keywords and phrases: Young's inequality, Hilbert-Schmidt norm, Positive semi-definite matrix, Kantorovich constant.

\section{REFERENCES}

[1] T. Ando, Matrix Young inequalities, Oper. Theory Adv. Appl., 75 (1995), 33-38.

[2] O. HirZallah And F. KitTaneh, Matrix Young inequalities for the Hilbert-Schmidt norm, Linear Algebra Appl., 308 (2000), 77-84.

[3] XING-KAI HU, Young type inequalities for matrices, J. East China Norm. Univ. Natur. Sci., 4 (2012), $12-17$.

[4] F. Kittaneh And Y. ManasRah, Improved Young and Heinz inequalities for matrices, J. Math. Anal. Appl., 36 (2010), 262-269.

[5] M. SABABHEH, Interpolated Inequalities for Unitarily Invariant Norms, Linear Algebra Appl., 475 (2015), 240-250.

[6] M. Sababheh, A. Yousef And R. Khalil, Interpolated Young and Heinz inequalities, Linear and Multilinear Algebra, 63 (2015), 2232-2244.

[7] J. WU AND J. ZHAO, Operator inequalities and reverse inequalities related to the Kittaneh-Manasrah inequalities, Linear and Multilinear Algebra, 62 (2014), 884-894. 